\title{
Brentano's Evaluative-Attitudinal Account of Will and Emotion
}

\author{
Uriah Kriegel \\ Forthcoming in Revue Philosophique (invited special issue on Brentano)
}

In contemporary analytic philosophy of mind, Franz Brentano is known mostly for his thesis that intentionality is 'the mark of the mental' (Chisholm 1957, Crane 1998). Among Brentano scholars, there are also lively debates on his theory of consciousness (Kriegel 2003, Textor 2006) and his theory of judgment (Chisholm 1976, Simons 1987). Brentano's theory of will and emotion is less widely discussed, even within the circles of Brentano scholarship. In this paper, I want to show that this is a missed opportunity, certainly for Brentano scholars but also for contemporary philosophy of mind. Brentano's accounts of the will and of emotion are, I will argue, both insightful and creative, on the one hand, and strikingly plausible, upon reflection, on the other.

The contemporary literature on emotion is considerably larger and more contentious than that on the will. Accordingly, I will start with Brentano's theory of the will, and demonstrate its plausibility against the more peaceful background of current-day discussions of desire (§1). Importantly, however, Brentano offers a somewhat unified account of will and emotion, so I will attempt to leverage the apparent plausibility of his account of will to argue for a similar plausibility in his account of emotion (\$2). This will lead to the question of how will and emotion should be distinguished within the unified account - something Brentano has very interesting things to say about $(\S 3)$.

\section{The Will}


In contemporary analytic philosophy of mind, discussion of the will focuses on the nature of desire, intention, and action. But the most prominent of these notions is by far desire (see under: 'belief-desire psychology'). Accordingly, I start this section with a presentation of leading accounts of desire in the analytic literature. Later I will discuss Brentano's account as a particularly well-developed version of one of them.

A common account of desire in current philosophy of mind characterizes it in terms of functional role within the overall economy of mind. More specifically, the idea is that desire and belief are complementary states that together causally explain the occurrence of observable behavior. For example, if Aristide goes to the kitchen, open the fridge, and takes out a beer, we can causally explain this piece of behavior by citing (i) Aristide's desire for beer and (ii) his belief that by going through these sequence of actions he will obtain beer (see Davidson 1963). Within this picture, belief and desire are characterized in terms of complementary clusters of causal dispositions. Robert Stalnaker puts the picture crisply:

Belief and desire ... are correlative dispositional states of a potentially rational agent. To desire that $P$ is to be disposed to act in ways that would tend to bring it about that $P$ in a world in which one's beliefs, whatever they are, were true. To believe that $P$ is to be disposed to act in ways that would tend to satisfy one's desires, whatever they are, in a world in which $P$ (together with one's other beliefs) were true. (Stalnaker 1984: 15)

On this picture, desire is nothing but a cluster of distinctly motivational dispositions.

One problem with this account of desire is that it is too coarse: many mental states other than desire - indeed, mental states that have nothing to do with the will - have a similarly motivational role. Anger and rage move us to action all too fast and all too immediately, but are emotional rather than volitional states. The point is: it is true that the will is intimately connected to action, but some emotions are as well. Stalnaker's dispositional account really only divides mental states into two 
groups, which we may call 'cognitive' and 'conative.' There is still much work left to delimit the province of desire (and will) within the conative domain.

From Brentano's perspective, there is an even deeper problem with Stalnaker's dispositional account. Observe that Stalnaker, in line with the functionalist orthodoxy in analytic philosophy of mind, treats desires and beliefs as unobservable theoretical entities, posited for the purpose of explaining observable action. For Brentano, however, the phenomena of the will, including desire, are not in the first instance explanatory posits, a hidden explanans of an observable explanandum. Rather, they are a type of conscious experience we have first-person acquaintance with. Furthermore, what makes them phenomena of the will is itself manifest to inner perception (Brentano 1874: II, 83 [235]). ${ }^{1}$ This is not unreasonable: even if blindfolded, I can know immediately and noninferentially that I desire to eat ice cream rather than believe I eat ice cream. This at least suggests that I can introspect (or rather, in Brentano's terminology, inner-perceive) that which makes my state a desire rather than a belief. ${ }^{2}$ Accordingly, theorizing about the nature of desire should not be driven in the first place by considerations of action explanation. It should first seek an explicit and precise description of that which inner perception presents in an unarticulated and 'blurry' fashion. ${ }^{3}$

Another approach to desire in contemporary philosophy of mind construes it as the paradigmatic state with a world-to-mind direction of fit: whereas belief is the kind of state that is supposed to fit the way the world is, desire is the kind of state that the world is supposed to fit (Anscombe 1957, Searle 1983). In believing that I am eating chocolate, I am so to speak molding my mind to fit the worldly fact that I am eating chocolate; in desiring to eat ice cream, I am committing to molding the world so it fits my state of mind. The first kind of state tries to get the world right, the second tries to right the world (if you will).

From a Brentanian point of view, however, this approach to desire faces a number of problems. First, it is far from clear what direction of fit means; it is a suggestive metaphor, but unpacking it literally has proven quite difficult (Zangwill 
1998). Secondly, the most natural accounts of direction of fit construe it as a matter of functional role (Smith 1994), or cluster of causal dispositions, which would again raise the above issues. Thirdly, even if we grant that belief is supposed to fit the world, whereas desire is such that the world is supposed to fit it, this does not seem like a brute, inexplicable fact. On the contrary, it seems that something must explain it: there must be something about belief that makes it supposed to fit the world, and something about desire that makes it such that the world is supposed to fit it.

There is also a third approach to desire one finds in modern philosophy of mind, which approach dovetails much better with Brentano's thinking. This is the notion that desire is essentially evaluative: it represents what it does as good (in a suitably generic sense). When you desire chocolate, there is a palpable sense in which your desire presents the chocolate as good. Thus while a belief that $p$ and a desire that $p$ represent the same thing (have the same content), the former represents $p$ sub specie boni whereas the latter represents $p$ sub specie veri. Here is how Dennis Stampe puts it in his classic 'The Authority of Desire':

[W] hile the belief and the desire that $p$ have the same propositional content and represent the same state of affairs, there is a difference in the way it is represented in the two states of mind. In belief it is represented as obtaining, whereas in desire, it is represented as a state of affairs the obtaining of which would be good. This modal difference explains why a desire that $p$ is a reason to make it true that $p$, while the belief that $p$ is not. (Stampe 1987: 355; italics original)

We may put the idea by saying that desire is goodness-committal: it commits to the goodness of its intentional object. This is the thesis that in the contemporary literature often goes by the name 'the guise of the good.' Sergio Tenenbaum calls it the 'Scholastic view' and formulates as follows:

... just as theoretical attitudes such as belief express what the agent holds to be true even when the belief is false, the scholastic view claims that practical attitudes, such as intending, and acting itself, express what the agent holds to be good. (Tenenbaum 2009: 96)

In a similar vein, Graham Oddie writes: 'The desire that P is P's seeming good (or P's being experienced as good)' (Oddie 2005: 42). 
Interestingly, the dispositional account, the direction of fit account, and the evaluative account do not seem to be in competition with each other in the relevant literature. They seem to be treated, rather, as different facets of a single comprehensive picture of the nature of desire. Yet there is a substantive question as to which of these three characteristic features of desire - its motivational role, its world-to-mind direction of fit, and its evaluative character - is more fundamental and explains the others.

There are certain advantages to taking the evaluative dimension to be fundamental. First, nothing prevents desire's goodness-commitment from being an occurrent, inner-perceptible feature. This allows us to do justice to the fact that desire is something we are familiar with from our personal experience, not merely a theoretical posit that is experientially opaque to us. Secondly, as an occurrent feature of desire, goodness-commitment is well positioned to underlie and explain desire's characteristic dispositional properties. And indeed, it is natural to think that my desire for chocolate motivates me to mold the world so that I obtain chocolate precisely because it presents it as good that I should have chocolate. This may well capture the sense in which the world is 'supposed' to fit the mind in desire. The point is that while goodness-commitment is clearly a feature of desire, there are good reasons to take it to be the essential feature of desire, what makes it a desire. Desire's characteristic motivational role and direction of fit flow from its evaluative nature.

Brentano himself does not discuss the will primarily in terms of desire. Nonetheless, I will conduct the discussion as though he does, for the sake of continuity; we will revisit the relationship between will and desire with a more critical mindset in $§ 3$.

Brentano clearly has an evaluative account of will/desire: 'every [desire] takes an object to be good or bad' (Brentano 1874: II, 36 [199]). ${ }^{4}$ However, there is an important difference between Stampe's above view and Brentano's. Stampe maintains that desire is perception of the good. Brentano rejects this, for two 
reasons. First of all, he denies that goodness is the kind of thing that can be literally perceived: 'There is just no such thing as a sensation/perception (Empfindung) having for an object a quality called moral goodness; it is an ad hoc invention' (Brentano 1952: 120 [74]). Secondly, perception belongs with belief in the category of states that try to get the world right, not the 'conative' states to which desire belongs. To desire ice cream is not to believe that the ice cream is good. One can believe that the ice cream is good and not feel like having one, and one can want one without thinking it is good. The same would apply to perception of goodness, if such a thing existed. For Brentano, a desire for ice cream is a sui generis way of positively evaluating the ice cream, irreducible to perceptual and belief-like ways of doing so:

I do not believe that anyone will understand me to mean that [desires] are cognitive acts (Erkenntnisakte) by which the goodness or badness, value or disvalue, of certain objects are perceived (wahrgenommen); indeed I note explicitly, in order to make such an interpretation completely impossible, that this would be a complete misunderstanding of my real view. (Brentano 1874: II, 89 [239])

The question is how to characterize the sui generis way in which desire presents goodness.

The key to Brentano's answer is the contemporary distinction between content and attitude, which Brentano himself drew in terms of 'object' and 'mode.' In saying that desire presents the good, but in its own sui generis way, Brentano suggests that desire involves a distinctive attitudinal property, which 'encodes' desire's goodness-commitment. We may put the point as follows: my desire's commitment to the goodness of chocolate should be understood not as a matter of presenting chocolate-as-good, but of presenting-as-good chocolate. The goodness of the chocolate is not part of what my desire presents, but an aspect of how it presents. It is not the object of the desire, but a dimension of the subject's desiring relation to that object (in this case, the chocolate). As Brentano puts it:

The essence of will consists in approval or disapproval, hence in a taking-as-good (ein Gutfinden) or taking-as-bad (Schlechtfinden)... (Brentano 1874: II, 91 [241]) 
That is, the desire relates to chocolate through the presenting-as-good relation, a distinctive mode of intentionally relating to an object.

The attitudinal approach recommends itself very strongly in the case of desire. For clearly, in desiring chocolate one does not desire that chocolate be good. One simply desires the chocolate. The goodness is thus not part of what is being desired, it is not part of the content of the desire. And yet the desire commits to the chocolate's goodness. It must therefore be that goodness shows up as an aspect of the desire's attitude, of how the desire presents what it does, rather than of what the desire presents. We might say that the desire casts chocolate in a positive light rather than cast light on positive chocolate.

This is just the idea that the desire does not present chocolate-as-good but presents-as-good chocolate. The goodness is a modification of how the desire does the presenting. Accordingly, to desire $x$ is to adopt an attitude that somehow favors $x$, is pro $x$. In this respect, the modern notion of 'pro attitude' is very apt here: for Brentano, desires, indeed interest states more generally, do not just happen to be pro attitudes - it is their essential characteristic. ${ }^{5}$

We can appreciate the point by contrasting a desire for chocolate with a belief in or perception of chocolate's goodness. In the latter, goodness appears precisely as part of the state's content; in the former, it is merely attitudinal. Compare the intentional structure of the following four putative states:

Belief that chocolate is good :: $\quad$ present-as-true $<$ chocolate is good $>$ Perception of chocolate's goodness :: present-as-existent <chocolate's goodness> Desire for chocolate :: present-as-good <chocolate>

The element of goodness shows up in the content of the evaluative belief-that and perception (if such there be). Only in desire does it show up in the attitude. It is in this sense that desire involves essentially a sui generis mode of presenting the intentional object, one irreducible to the mode characteristic of belief and perception. 
This is something that modern proponents of the evaluative account of desire seem to have missed. In the above quotation, Stampe refers to the evaluative dimension of desire as 'modal' - presumably in the sense of being attitudinal. Nonetheless, he struggles with the difference between desire and evaluative belief, worrying that in these two cases 'one and the same state of affairs is represented "in the same way," that is, as having the same property' (Stampe 1987: 356). And that leads him to suggest that desire, unlike evaluative belief, is direct perception of value. But Stampe's supposed problem rests on a mistake. As we have just seen, desire and evaluative belief do not present their object in the same way (in the relevant sense): only the former presents-as-good its object. For that matter, they do not even present the same object: the belief presents chocolate's being good, the desire just chocolate.

Brentano's account of desire can be captured in the following pair of theses:

Evaluative-D :: Any desire D for an object $\mathrm{O}$ essentially commits to the goodness of 0 .

AtTitudinal-D :: A desire D's commitment to the goodness of an object $\mathrm{O}$ is an attitudinal property of $\mathrm{D}$.

Note that Evaluative-D is an essentiality claim, not just a universal or even modal one. It implies that all desires are necessarily goodness-committal, but that can be accepted by functional-role accounts of desire as well. Where it goes beyond the functional-role accounts is in claiming that it is of the essence of desire to commit to its object's goodness. At the same time, Evaluative-D is compatible with accounts of desire that build the evaluation into its content. A belief in the goodness of world peace is also goodness-committal, but through its content. This is what is ruled out by ATtitudinAL-D. The upshot is an account of desire that construes desire as essentially goodness-committal in virtue an attitudinal feature; call this the evaluative-attitudinal account. 
What is Brentano's argument for the evaluative-attitudinal account? The answer, I am afraid, is that he has no direct argument. He dedicates $\S 3$ of Chap. 8 of Book II of Psychology from an Empirical Standpoint to defending the view, but the defense simply appeals to authority: Lotze, Kant, Mendelssohn, Aristotle, and Aquinas all shared the view, we are told, so the view 'can be regarded as generally accepted (anerkannt)' (Brentano 1874: II, 90 [241]). One gets the impression, however, that for Brentano, central to the view's attraction is the way it fits into an elegant bigger picture. In particular, the symmetry between an account of desire in terms of presenting-as-good with an account of belief in terms of presenting-as-true indirectly recommends both. He certainly celebrates the parallelism:

If something can become the content of a judgment in that it can be accepted as true or rejected as false, it can also become the object of a [desire] in that it can be agreeable (genehm) (in the broadest sense of the word) as something good, or disagreeable (ungenehm) as something bad. (Brentano 1874: 239 [II, 88-9])

Such 'top-down' dialectical pressures rarely play a role in analytic philosophy of mind, but are highly operative in Brentano's thinking.

Our discussion has raised, however, certain independent considerations in support of Brentano's account. These considerations can be divided into those that motivate the evaluative approach in general and those that support the attitudinal version of the approach. What motivates the evaluative approach in general is the way it avoids the problems attending rival approaches, in particular the functionalrole and direction-of-fit approaches. And what motivates the attitudinal approach to desiderative evaluation is the simple observation that in desiring chocolate one is not desiring that chocolate be good, but only desires the chocolate. Given that the desire nonetheless commits to the chocolate's goodness, the only way to accommodate this simple observation is to build desire's goodness-commitment into its distinctive attitude.

It might be objected that desire cannot be essentially goodness-committal, since we routinely desire what we know full well to be bad (see Velleman 1992). 
One may want the boss to be embarrassed, even though one takes such embarrassment to be bad prudentially, morally, and otherwise. In response, however, I would claim that such cases involve conflicting evaluations. The desire still presents-as-good boss-embarrassment, but is accompanied by an evaluative belief whose content is that it would be bad if the boss were embarrassed. That is, the belief presents-as-true that boss-embarrassment is bad. This is perfectly compatible, in a psychological sense, with the occurrence of a state that presents-asgood boss-embarrassment - as compatible with seeing (or seeming to see) the spoon bent in the water while believing that the spoon is not bent.

\section{Emotion}

The philosophy-of-mind literature on emotion is much larger than that on desire. But here too, a stubborn strand casts emotional states as essentially evaluative. Indeed, the evaluative approach to emotion has gained considerable traction toward the end of the twentieth century. Consider this assessment:

Most recent accounts of the structure of emotion, despite their differences, agree that emotions (somehow) present the world to us as having certain value-laden features. Following their lead, we will say that emotions involve evaluative presentations. (D'Arms and Jacobson 2000: 66)

Admiring Shakespeare, liking Messi, respecting one's colleague, and loving one's child are all emotional states that evaluate their objects positively; resenting the boss, disliking Donald Trump, feeling indignant over the burkini ban, and being angry at oneself for forgetting one's passport evaluate their objects negatively. The claim of the evaluative account is that emotions involve such evaluations universally, necessarily, and indeed essentially.

Brentano appears to adopt such an evaluative account of emotion. We can see this from the fact that he considers 'emotion' one appropriate name for the 
category of mental phenomena he contrasts with judgments, and for which he offers the evaluative account. In one place he writes:

A single appropriate expression is lacking most of all for the third fundamental class [of mental states], whose phenomena we designated as emotions (Gemüthsbewegungen), as phenomena of interest, or as phenomena of love... Just as every judgment takes an object as true or false, so in an analogous way every phenomenon belonging to this third class takes an object as good or bad. (Brentano 1874: II, 35-6 [199])

It would seem, then, that Brentano does not offer - at least not in the Psychology two different accounts, one for desire and for emotion. Rather, he offers a single account that is supposed to apply to a category of mental phenomena that covers emotions and desires alike. To that extent, the kind of evaluative account we have encountered in $\S 1$ is supposed to be equally an account of emotion - one that anticipates, then, the more recent evaluative theories of emotion.

These recent evaluative accounts typically come in two varieties. One casts emotions as evaluative judgments (Solomon 1976): to admire Shakespeare is to judge him admirable, where admirability is a species of goodness (being admirable is a way of being good, in a suitably generic sense of that term). The other casts emotions as evaluative perceptions (de Sousa 1987): to dislike Donald Trump is to perceive him as dislikable, where dislikability is a species of badness (a way of being bad). As we have seen, however, Brentano does not take mental states belonging to the relevant category to be evaluative judgments or perceptions, but to constitute a sui generis category characterized by a distinctive intentional mode. For him, then, the evaluative dimension of emotion cannot consist in emotion presenting normative entities. Rather, it must be a matter of emotions normatively presenting regular, nonnormative entities. As he puts it:

... the expressions which we use here [to designate the evaluative character of emotion] do not mean that, in the phenomena of this class, goodness is ascribed to something which is agreeable as good, and badness is ascribed to something which is disagreeable as bad; rather, they too denote a particular way in which mental activity refers to a content. (Brentano 1874: II, 90 [240]) 
My admiration of Shakespeare does not present Shakespeare as good so much as presents-as-good Shakespeare. My resentment does not present the boss as bad, but presents-as-bad the boss.

Accordingly, we may formulate Brentano's account of emotion on the pattern of his account of desire. One initial difference, though, is that while desire always presents-as-good, emotions divide into those that present-as-good and those that present-as-bad. A desire for chocolate presents-as-good chocolate, but it would be a mistake to think that a desire for avoiding vodka presents-as-bad vodka; rather, it presents-as-good vodka-avoidance. We can see this from the fact that avoidance shows up in the content of the desire. That is what the desire just mentioned is a desire for: the avoidance of vodka. It is an open question whether there are states of the will other than desire that essentially present-as-bad. If aversion is a state of the will, it would be a case in point: aversion of vodka certainly presents-as-bad vodka. In any case, emotions clearly divide into positive and negative: some cast their objects in a positive light (joy, love, admiration), others in a negative light (fear, frustration, personal dislike or antipathy).

A formulation of Brentano's account of emotion paralleling his account of the will would therefore look like this:

Evaluative-E :: Any positive (negative) emotion E about an object $\mathrm{O}$ essentially commits to the goodness (badness) of 0 .

AtTitudinal-E :: An emotion E's commitment to the goodness (badness) of an object $\mathrm{O}$ is an attitudinal property of $\mathrm{E}$.

We may call this the evaluative-attitudinal account of emotion. Although evaluative approaches to emotion are common in contemporary analytic philosophy of mind, their evaluative version is less so (though see Denonne and Teroni 2012 Chap.7).

If one does adopt an evaluative-attitudinal account of emotion, but also an evaluative-attitudinal account of will, then one faces the obvious question of what (if anything) distinguishes will and emotion - a question we turn to in $\S 3$. 
The main motivation for the attitudinal twist on the evaluative theory of emotion is, again, that the value is not part of what is presented in emotion, what is emoted about. When you admire Shakespeare, it is just Shakespeare that you admire. It is not Shakespeare's admirability that you admire, and more generally not his goodness that you emote about. Perhaps you admire Shakespeare in virtue of his (relevant type of) goodness. That would mean that Shakespeare's goodness is the cause or reason of your admiration. All the same, Shakespeare's goodness is not the object of your admiration. The object of your admiration is just Shakespeare. Accordingly, any evaluation of Shakespeare involved in admiring him cannot come from the content of the admiration. It must be built into the admiring attitude. To admire Shakespeare is thus not to be in a mental state that presents Shakespeareas-admirable, but to be in one that presents-as-admirable Shakespeare. The property of presenting-as-admirable is an attitudinal property. It is related to the property of presenting-as-good as species to genus: presenting-as-admirable is $e o$ ipso presenting-as-good in the same sense being a cat is eo ipso being a mammal. Just as admirability itself is a species of goodness, presenting-as-admirable is a species of presenting-as-good.

The same applies to negative emotions. When one is afraid of a dog, one experiences the dog as dangerous. But one's fear is not a fear that the dog be dangerous. No, it is simply a fear of the dog. The element of danger must therefore be attitudinal: one's fear presents-as-dangerous the dog. And presenting-asdangerous is a species of presenting-as-bad.

This is important, because most arguments against evaluative accounts of emotion target the claim that values are presented by emotions (see, e.g., Dokic and Lemaire 2013). But Brentano's evaluative account does not claim that values are presented by emotions, so it is not vulnerable to arguments of this sort. Opponents of evaluative theories must therefore proffer some new argument against the attitudinal version of the evaluative account. 


\section{Distinguishing Will and Emotion}

Having defended an evaluative-attitudinal account both of will and of emotion, Brentano faces the problem of how to distinguish the two. Since they have the same underlying nature, he takes them to belong to a single 'fundamental' category (Grundklasse). It remains that there seems to be some real difference between emotion and volition, and this difference needs accounting for.

As one might expect, one difference Brentano points out concerns a link to action:

Every willing (Wollen) has to do with an action (Tun) we believe to lie within our power, with a good which is expected to result from the willing itself. (1874: II, 103 [249])

Since all interest states present-as-good their object, they involve a belief that it would be good if their object existed. Sometimes, however, the subject believes not just that it would be good if the relevant object existed, but also that this would be a good brought about by herself; when this is the case, the interest state in question is a will state (see also Brentano 1952: 219 [137]). The idea might be, then, that emotional and volitional states differ in that the latter involve a belief the former do not.

I suspect, however, that for Brentano this belief-based difference is only a symptom of a deeper, more essential difference. For note that this difference between volitional and emotional states is a cognitive difference, whereas volitional and emotional states are noncognitive. If volitional states were composite states with a cognitive component, this cognitive component could certainly be part of their deep nature. But Brentano seems to think that no interest states have a cognitive component essentially. At most they involve cognitive accompaniments. Assuming, then, that the belief that a good will result from our own activity is merely an accompaniment of volitional states, it would follow that distinguishing volitional from emotional states in terms of this accompaniment would be a purely 
extrinsic distinction. Yet surely there is an intrinsic difference between the two - a difference grounded in their own nature rather than in their accompaniments.

In a 1907 piece titled 'Of Loving and Hating,' Brentano seems to suggest the following way of distinguishing will and emotion:

There are things which are discordant/incompatible (unverträglich) with others, as when for example it is impossible for the selfsame physical thing (Körper) to be at once round and square, at rest and in motion, liquid and solid, red and blue. Whoever wants or wishes (will oder wünscht) that an object be one of these things cannot at the same time reasonably (vernünftiger Weise) want or wish that it be one of the others. But he can at the same time enjoy/be pleased (ein Gefallen finden) with it being round and with it being square etc. (Brentano 1907: 156 [150]; my italics)

In his lecture notes for his Vienna practical philosophy course, which he wrote originally in 1876 and refined and added to until 1894, he writes:

I can love [i.e., have a positive emotion toward] things that are incompatible (unvereinbar) with one another, for example doing sums and writing. The one [positive emotion] does not preclude/rule out (schließt aus) the other. In contrast, in any particular case I can decide on/make up my mind in favor of (mich entscheiden) one of the two. These decisional acts (Entscheidungakte) are not compatible with one another. (Brentano 1952: 218-9 [137])

It is in these passages, I contend, that we get a glimpse into Brentano's ultimate account of the will/emotion distinction. Here is how I understand the account.

Imagine you are finishing a hefty restaurant meal and have to choose among the dessert options. The chocolate cake does not appeal to you, but either the banana split or the crème brûlée would be very nice. You feel like having the banana split, but you also feel like having the crème brûlée. Each feeling presents-as-good its respective object. Having both the banana split and the crème brûlée would be too much, however, and anyway you cannot afford it; so you have to choose. This is where the will comes in. Conflicting emotional states, such as of the feeling-like- $\varphi$ ing kind, can rationally coexist. But a decision or intention to $\varphi$ cannot rationally coexist with an incompatible decision or intention. The general idea, then, is that emotional states differ from volitional in that conflicting emotional states can 
rationally coexist whereas conflicting volitional states cannot. The principled distinction may therefore be represented as follows:

Distinction $_{1}$ :: For any interest attitude A, A is an emotional attitude iff there is a pair of objects $x$ and $y$, such that (i) $x$ and $y$ cannot coexist and (ii) it is possible to rationally bear A both to $x$ and to $y$; A is a volitional attitude iff there is no such pair.

Some clarifications. First, as far as DisTinCTION1 goes, 'intentional object' covers everything that can be desired or emoted about, not only concrete particulars; thus actions, events, and states of affairs are all potential intentional objects. (At the same time, for Brentano himself only concrete particulars will be the objects of our intentional states, just as they exhaust the objects of judgment.) Secondly, incompatibility is interpreted here as incompossibility, but in truth a subtler story is probably called for, where relations of probabilifcation and improbabilifcation play a role. ${ }^{6}$ Thirdly, note that our distinction is between will and positive emotion; negative emotion is distinguished from desire more straightforwardly in terms of the content of preference: a negative emotion toward $x$ implies a preference for $x$ 's nonexistence over its existence. In fact, fourthly, our distinction is between will and mere positive emotion. Obviously, a person may both desire and have positive emotion about $x$ (e.g., both intend to, and be happy about, giving to charity). Fifthly, a person may prefer $x$ over $y$ without preferring $x$ 's existence over its nonexistence namely, in 'lesser evil' cases.

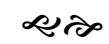

One disadvantage of DISTINCTION 1 is that it does not make explicit the Brentanian emphasis on drawing the will/emotion distinction in attitudinal terms. Relatedly, it does not seem to cite an intrinsic difference between emotional and volitional states.

Perhaps, however, there is a way to build the distinction pointed out in DisTINCTION $_{1}$ into specific attitudes intrinsic to emotional and volitional states. In contemporary moral philosophy, there is a familiar distinction between prima facie 
and all-things-considered normativity. Against certain critics of deontological theories, W.D. Ross (1930) argued that we do have a duty not to harm others, for example, but it is a prima facie rather than all-things-considered duty. Thus, if harming a terrorist might save a thousand innocent civilians, the prima facie duty not to harm others may not proscribe harming the terrorist. In that scenario, harming the terrorist might be prima facie wrong but ultima facie (all-thingsconsidered) right. Conversely, helping an old lady cross the street is prima facie good, but if it slows traffic to the point that an ambulance arrives to hospital too late to save someone, then it is ultima facie bad. Now, to say that helping the old lady cross the street is prima facie good seems to mean this: in abstraction from all other considerations, the existence of such help is better than - preferable over - the nonexistence of such help. And to say that it is ultima facie bad is to say this: once we take into account all other relevant considerations, there is some scenario in which the old lady is not helped that is better than - preferable over - the scenario in which she is helped.

This distinction between prima facie and ultima facie goodness may be used to formulate succinctly Brentano's distinction between will and emotion in attitudinal terms. The idea is that positive emotions cast their objects in a primafacie-positive light, since for something to be prima facie good just is for it to be such that its existence is preferable over its nonexistence. So in preferring white wine over no wine, my happiness about white wine frames it as a prima facie good. In contrast, acts of the will cast their objects in an all-things-considered-positive light, since for something to be ultima facie good just is for it to be preferable over all alternatives. So in preferring red wine over any other drink, my intention to have red wine frames it as an all-things-considered, ultima facie good. The point is this: just as generic goodness comes in two varieties, prima facie and ultima facie, the generic attitudinal property of presenting-as-good comes in two varieties: presenting-as-good ${ }_{\mathrm{PF}}$ (for 'prima facie good') and presenting-as-good ${ }_{\mathrm{UF}}$ (for 'ultima facie good'). All positive interest states generically present-as-good their intentional objects, but some specifically present-as-good $\mathrm{PF}_{\mathrm{F}}$ their objects while others present- 
as-good $\mathrm{UF}$ theirs. The former are positive emotions, the latter states of the will. That is:

DisTinCTION 2 :: For any interest attitude A toward object $x, A$ is an emotional state iff A presents-as-good $\operatorname{PF} X$ (or presents-as-bad ${ }_{\mathrm{PF}} X$ ); $\mathrm{A}$ is a volitional state iff A presents-as-good ${ }_{\mathrm{UF}} X$.

To present-as-good $\mathrm{PF}_{\mathrm{PF}} x$ is to frame $x$ as superior to its absence; to present-as-good $\mathrm{dF}_{\mathrm{UF}}$ is to frame $x$ as superior to all relevant alternatives. Note that an outcome can be good $_{\mathrm{UF}}$ without being good $\mathrm{PF}_{\mathrm{PF}}$, namely in lesser evil cases. (It is only having considered all things that Roosevelt came to see entering WWII as a good thing to do; nothing about joining a war in which upwards 300,000 American soldiers died strikes one prima facie as good.) It is for this reason that among will states we find the state of being willing to do something. Being willing to do something involves having a will state despite lacking a positive emotion, as when I find no pleasure in chairing the next session, but am willing to do so because someone has to.

There is an immediate objection to this account of the distinction. In addition to cases of conflicting emotions, we are all familiar with cases of conflicting desires. Indeed, there are cases where (i) two of our desires conflict, (ii) we are aware that they conflict, but (iii) it is rational to hold on to both. After all, this is how moral dilemmas arise. Consider Sartre's renowned student, who faces the choice between leaving Paris to fight the Nazis and staying in Paris to look after his ailing mother (Sartre 1946). Both the desire to fight the Nazis and the desire to tend to his mother are commendable, but they are incompatible. The decision which one to pursue is not an easy one, and at least for a while, the student can reasonably desire both contrary to what Brentano appears to claim. Accordingly, both desires merely present-as-good $\mathrm{PF}$ their respective objects.

At the same time, there seems to be an important insight in Brentano's appeal to the prima facie/all-things-considered distinction in drawing the 
emotion/will distinction. Certainly it is true that our pro attitudes divide into two importantly different groups, depending on whether they cast their objects as prima facie or all-things-considered good. When it comes time to try and implement his pro attitudes in the world, Sartre's student must choose between the two options, thus entering a new kind of mental state that surpasses his conflicting desires and paves the way to action. Entering that mental state is the beginning of mobilizing the will.

How are we to resolve these tensions? Two strategies present themselves. The first strategy is to deny that desire is a volitional state and argue that, on reflection, it turns out to be an emotional state. The other is to renounce the notion that there is a sharp line between will and emotion and placing desire in the 'gray area' between them. Although I think both we can find support for both strategies in the Brentanian corpus, here I will focus on the former, which is more straightforward.

To see the rationale for the reclassification strategy, we should first observe that although in analytic philosophy of mind desire is taken as the paradigmatic state of the will, other philosophical traditions, notably the phenomenological tradition, have opted for other paradigms. According to Paul Ricœur, for example, the paradigmatic will state is decision: it is in deciding to $\varphi$ that we exercise our will in the fullest sense (Ricœur 1950). It is in decision that the mind passes from considering several potential good courses of action to settling on one:

What is remarkable is that the decision, cut off from its execution by a delay, by a blank, is nonetheless not indifferent to its execution; when I have decided to make a delicate move, I feel myself somehow charged, in the way a battery is charged: I have the power to act, I am capable of it. (Ricœur 1950: 62)

Moreover, Ricœur's reason for this is precisely that desire involves only a hypothetical pull to action, whereas decision's commitment to action is categorical (Ricœur 1950: 70). It is essential to my desire for crème brûlée that if no other considerations outweigh it, it would lead to my eating the crème. Thus in desire the 
connection to action is conditional or hypothetical: the desire presents the action as to be performed if there are no countervailing considerations/desires. In contrast, a decision's connection to action is categorical: in making the decision to eat the crème brûlée, I commit to eating it, period. The commitment is unconditional.7 This is what makes decision an exercise of the will. Likewise, if Sartre's student finally decides to go to war, he settles into a mental state that presents-as-good $\mathrm{d}_{\mathrm{UF}}$ that option. That option is no longer cast as good only in a sense that allows other, incompatible options to also be good. It is cast as all-things-considered good (see Kriegel 2015 Chap. 2).

This may open the door to the notion of reclassifying desire as an emotional state. Desire is after all a passion rather than an action, something we find ourselves with rather than something that issues from exercise of our will. In contrast, when we make a decision we precisely exercise our will; to that extent, decision is a phenomenon of the will par excellence. There is thus a bright line between the two phenomena. As Wallace puts it:

... intentions, decisions, and choices are things we do, primitive examples of the phenomenon of agency itself. It is one thing to find that one wants some chocolate cake very much, ... quite another to resolve [i.e., decide] to eat a piece. The difference, I would suggest, marks a line of fundamental importance, the line between the passive and the active in our psychological lives. (Wallace 1999: 637)

This is especially true given that anything one 'feels like' doing can be described as a desire of one's. So one option for Brentano is to simply deny that desire is a state of the will. The phenomenon of conflicting desires would then be seen as to be expected. ${ }^{8}$

In some places, Brentano too highlights the role of decision, rather than desire, in the will. In one place, he even states that 'every act of the will (Wollen) constitutes a decision' (1952: 219 [137]). Admittedly, this does not quite imply a reclassification of desire as an emotion. But there are passages in Brentano that clearly support such reclassification. Recall Brentano's claim that volitional states 
involve the belief that their intentional object 'lie within one's power' (1874: II, 103 [249]). In several places, Brentano is explicit that desire need not involve such a belief. For example:

Kant indeed defined the faculty of desire (Begehrung) simply as 'the capacity to bring into existence the objects of one's presentations through those presentations.'... This is why we find in Kant that curious claim that any wish (Wünsch), even if it were recognized to be impossible, such as the wish to have wings for example, is an attempt to obtain what is wished for and contains a presentation of our desire's causal efficacy. (1874: II, 117 [259])

Brentano is thus committed to the first two premises of the following straightforward argument: for any subject $S$ and object $x, 1$ ) necessarily, if $S$ has a volitional state directed at $x$, then $S$ believes that $S$ can obtain $x ; 2$ ) possibly, $S$ desires $x$ and $S$ believes that $S$ cannot obtain $x$; therefore, 3 ) desiring is not a volitional state. ${ }^{9}$

\section{Conclusion}

Brentano's overall theory of will and emotion can be summarized in terms of three theses:

$\left(\mathrm{T}_{1}\right.$ ) What makes a mental state $\mathrm{M}$ a state of the will (a 'volitional' state) is that $\mathrm{M}$ exhibits a particular evaluative attitudinal property, namely, what we called presenting-as-ultima-facie-good.

$\left(\mathrm{T}_{2}\right)$ What makes a mental state $\mathrm{M}$ an emotional state is that $\mathrm{M}$ exhibits another evaluative attitudinal property, namely, presenting-as-prima-facie-good.

$\left(\mathrm{T}_{3}\right)$ Because the evaluative attitudinal properties characteristic of volitional and emotional states are species of a single generic attitudinal property, namely presenting-as-good, volitional and emotional states belong to a single natural kind of mental states. 
Together, these amount to a unified evaluative-attitudinal account of will and emotion, with a clear distinction between them flowing naturally from the overarching framework.

I promised the reader at the opening that Brentano's theory of will and emotion is both original and plausible. The view's originality is probably clear by now. In contemporary philosophy of mind, only Bennett Helm (2001) has defended a unified evaluative account of will and emotion. ${ }^{10}$ (And the particulars of Brentano's attitudinal picture, including Brentano's specific attitudinal distinction between will and emotion, are absent in Helm.) But despite its originality, Brentano's picture has much to recommend it. On the one hand, it is both phenomenologically and architecturally evident that states of will and emotion involve evaluations of their objects: phenomenologically, wanting or liking or being happy about something clearly embodies a felt positive stance toward it; architecturally, the special motivational role and action-guiding force of will and emotion suggest that they evaluate their objects as worth pursuing or avoiding. At the same time, the evaluations involved do not seem to be part of the contents willed or emoted about, but rather appear built into the very attitudes we take toward those contents. This, again, is both phenomenologically plausible and manifest from the manner we ordinarily report our volitional and emotional states: typically, we both feel and say that we are happy to see our friend, not that we are happy that seeing our friend is good. Within this framework, the difference between being happy to see one's friend and deciding to see one's friend is rahter elegantly captured by the difference between two species of attitudinal evaluation, a prima facie one and an all-things-considered one. ${ }^{11}$

\section{References}

- Anscombe, G.E.M. 1957. Intention. Oxford: Basil Blackwell. 
- Brentano, F.C. 1874. Psychology from Empirical Standpoint. Trans. A.C. Rancurello, D.B. Terrell, and L.L. McAlister. London: Routledge, 1995.

- Brentano, F.C. 1889. The Origin of our Knowledge of Right and Wrong. Trans. R.M. Chisholm and E.H. Schneewind. London: Routledge \& Kegan Paul, 1969.

- Brentano, F.C. 1907. 'Of Loving and Hating.' In Brentano 1889.

- Brentano, F.C. 1952. The Foundation and Construction of Ethics. Ed. F. Mayer-Hillebrand. Trans. E.H. Schneewind. Routledge \& Kegan Paul, 1973.

- Chisholm, R. 1957. Perceiving: A Philosophical Study. Ithaca, NY: Cornell University Press.

- Chisholm, R. 1976. 'Brentano’s Nonpropositional Theory of Judgment.' Midwest Studies in Philosophy of Mind 1: 91-95.

- Crane, T. 1998. 'Intentionality as the Mark of the Mental.' In A. O’Hear (ed.), Contemporary Issues in Philosophy of Mind. Cambridge: Cambridge University Press.

- D'Arms, J. and D. Jacobson 2000. 'Sentiment and Value.' Ethics 110: 722-748.

- Davidson, D. 1963. 'Actions, Reasons, and Causes.' Journal of Philosophy 60: 685-700.

- Deonna, J. and F. Teroni 2012. The Emotions. Abingdon and New York: Routledge.

- Dokic, J. and S. Lemaire 2013. 'Are Emotions Perceptions of Value?' Canadian Journal of Philosophy 43: 227-247.

- Helm, B.W. 2001. Emotional Reason. Cambridge: Cambridge University Press.

- Kriegel, U. 2003. 'Consciousness as Intransitive Self-Consciousness: Two Views and an Argument.' Canadian Journal of Philosophy 33: 103-132.

- Kriegel, U. 2015. The Varieties of Consciousness. Oxford and New York: Oxford University Press.

- Ricœur, P. 1950. Le volontaire et l'involontaire. Paris: Aubier.

- $\quad$ Ross, W.D. 1930. The Right and the Good. Oxford: Oxford University Press.

- Sartre, J.-P. 1946. Existentialism is a Humanism. London: Methuen, 1948.

- $\quad$ Schueler, G.F. 1995. Desire. Cambridge MA: MIT Press.

- Searle, J.R. 1983. Intentionality. Cambridge: Cambridge University Press.

- Simons, P.M. 1987. 'Brentano's Reform of Logic.' Topoi 6: 25-38.

- Smith, M. 1994. The Moral Problem. Oxford: Blackwell.

- Solomon, R. 1976. The Passions. New York: Doubleday.

- de Sousa, R. 1987. The Rationality of Emotion. Cambridge MA: MIT Press.

- $\quad$ Stalnaker, R. 1984. Inquiry. Cambridge MA: MIT Press.

- Tenenbaum, S. 2009. 'Knowing the Good and Knowing What One is Doing.' Canadian Journal of Philosophy 39 (supplement): 91-117.

- Textor, M. 2006. 'Brentano (and some Neo-Brentanians) on Inner Consciousness.' Dialectica 60: 411-432.

- Valleman, D. 1992. 'The Guise of the Good.' Noûs 26: 3-26. 
- Wallace, R.J. 1999. 'Addiction as a Defect of the Will.' Law and Philosophy 18: 621-654.

- Zangwill, N. 1998. 'Direction of Fit and Normative Functionalism.' Philosophical Studies 91: 173-203.

${ }^{1}$ As we will see later in this section, Brentano takes as essential to desire the specific mode of presenting or referring to the intentional object. Because this mode is shared by feelings of pain and pleasure, Brentano considers the two types of state as belonging to the same fundamental mental category. Against this background, he writes: 'Inner perception, we say, reveals the absence of a fundamental distinction [between feeling and will].... Here it reveals an essential agreement in the kind of reference to an object ...' (Brentano 1874: II, 83 [235])

2 Brentano draws a distinction, crucial in his philosophy of mind, between introspection and inner perception (Brentano 1874: I, 40-1 [29-30]). I am going to simplify the discussion by ignoring this distinction, though it is an important one in its own right.

${ }^{3}$ In addition, Brentano rejects the existence of dispositional mental states. He accepts that we have the kind of tacit dispositions commonly attributed to subjects, but insists that 'these are not mental phenomena' (Brentano 1874: I, 86 [60]); instead, they are brute neurophysiological phenomena.

4 Page references refer first to the German edition of Brentano's writings and in bracket to the English edition. In the case of the Psychology from an Empirical Standpoint (Brentano 1874), the classic edition is the 1924 one edited by Oskar Kraus, which is in two volumes. Accordingly, I refer also to the number of the volume.

${ }^{5}$ The only connotation of the term 'pro attitude' we must explicitly cancel here is that this is a dispositional state. For Brentano (1874: 60 [I, 86]) rejects the existence of dispositional mental states. Accordingly, he takes desire and other interest states to be occurrent conscious states. They are occurrent pro attitudes, then.

${ }^{6}$ If we introduce gradient incompatibility, whereby $x^{\prime}$ s existence probabilifies $y^{\prime}$ s nonexistence, we could also define a continuum of states between pure emotions and pure desires. But this is not strictly forced on us: some bright line might be drawn somewhere along the envisaged continuum. In that case, the will/emotion distinction remains dichotomous.

7 This does not mean that decisions cannot involve conditional commitment to action. It is just that when they do, the conditionality must be part of their content. I can certainly decide that I want the crème brûlée unless it takes 20 extra minutes to prepare. Here I enter a mental state with an unconditional attitudinal commitment to a conditional content. (This is to be distinguished from a case where I simply decide to get the crème brûlée but am later told that it will take an extra 20 minutes to prepare, whereupon I make a new decision. This is not a case of a conditional decision, but rather of a change my mind from one unconditional decision to another.)

${ }^{8} \mathrm{~A}$ more nuanced version of this move would distinguish two notions of desire and place one in the emotional domain and the other in the volitional domain. Thus, in his book Desire, G.F. Schueler distinguishes between two notions of desire: 'In one sense of "desire," ... from the fact that an agent intentionally performed some action, it follows that he or she wanted to do whatever it was that action was supposed to achieve. But in the other perfectly good sense of "desire," there is nothing at all problematic or mysterious about people doing things they have no desire to do, things they don't 
want to do at all. I would say, for instance, that I had no desire to attend a meeting at my son's school the other evening. I would much rather have stayed home and read. But I did attend the meeting because I believed I had a responsibility to do so... (Schueler 1995: 29; italics original) In one sense of the term, Schueler clearly wanted to go to the meeting - or else he would not have ended up there. But in another sense, he did not want to go at all - there are any number of relevant alternatives he preferred. The first notion of desire, somewhat theoretically motivated within the 'belief-desire psychology' framework, conceives of desire as committed to ultima facie goodness. The second notion of desire, more pretheoretic, conceives of desire as committed only to prima facie goodness. With this distinction in place, Brentano could say this: desire construed in the first way is a bona fide volitional state, but does not allow 'conflicting desires'; conflicting desires are possible if we operate with the second notion of desire, but in that sense desire is rather an emotional state. Either way, DISTINCTION $_{3}$ is unaffected by the objection from conflicting desires.

${ }^{9}$ Clearly, Brentano tends to make the point with emphasis on wishing, which is more antecedently amenable to reclassification as an emotion than desiring; but equally clearly, he plans to extend the same treatment to the latter as well.

${ }^{10}$ Helm offers this also as part of an integrated account that covers even pleasure and pain. Interestingly, so does Brentano! See Brentano 1874: II, 92-3 [242].

11 For comments on a previous draft, I am grateful to Julien Deonna, Guillaume Fréchette, Anna Giustina, Josh Shepherd, and Fabrice Teroni. I have also benefited from presenting drafts of this chapter to two different audiences at École Normale Supérieure and to one at the University of Geneva. I am grateful to the audiences there, in particular Mathilde Berger-Perrin, Romain Bourdoncle, Géraldine Carranante, Lionel Djadaojee, Vincent Grandjean, Maria Gyemant, Lylian Paquet, and Justin Winzenrieth. This work was supported by the French National Research Agency's grants ANR-11-0001-02 PSL* and ANR-10-LABX-0087, as well as by grant 675415 of the European Union's Horizon 2020 Research and Innovation program. 